\title{
Perancangan Animasi 3D Objek Wisata Museum Budaya Watu Pinawetengan
}

\author{
Taufan Yusuf Aslah ${ }^{(1)}$, Hans F. Wowor ${ }^{(2)}$, Virginia Tulenan ${ }^{(3)}$ \\ Teknik Informatika, Universitas Sam Ratulangi, Manado, Indonesia. \\ Email: Taufan.aslah@gmail.com, Hanswowor@unsrat.ac.id, Virginia.tulenan@gmail.com
}

\begin{abstract}
Abstrak --- Saat ini banyak objek wisata yang bermunculan di berbagai tempat, namun kebanyakan hanya berupa tempat rekreasi hiburan keluarga yang kurang memberikan nilai pendidikan atau nilai edukasi bagi para pengunjungnya. Sementara objek wisata seperti museum budaya watu pinawetengan yang mempunyai nilai sejarah tinggi justru tidak banyak kita jumpai, selain itu pengunjung objek wisata museum budaya watu pinabetengan menurun, untuk menambah daya tarik pengunjung museum maka dibuatlah sebuah video edukasi dengan tampilan camera tracking yaitu Animasi 3D Objek Wisata Museum Budaya Watu Pinawetengan.

Pada pembuatan video Animasi 3D ini, proses dimulai dengan menentukan ide dan tema, wawancara di museum watu pinawetengan, mengumpulkan data hingga merancang storyboard. Setelah itu melakukan proses modeling, teksturing, animating camera operation hingga pada tahap rendering dengan meggunakan aplikasi blender, kemudian menjadi potongan-potongan adegan dari video animasi 3 dimensi. Setelah proses pembuatan adegan selesai, maka dilanjutkan proses penggabungan adegan yang telah dibuat di aplikasi blender dan penambahan teks serta audio menggunakan software Adobe premiere pro cs5 dan adobe auditions. Tahap terakhir adalah proses final rendering yang menghasilkan video Animasi 3 dimensi secara keseluruhan mejadi format file .mp4 beresolusi $960 \times 540$ dengan frame 23 frame/second pixel berdurasi 08 menit 00 detik dan ukuran file 2.52 GB
\end{abstract}

Kata Kunci : Animasi 3D, Budaya, Camera Tracking, Museum, Objek Wisata, Watu Pinawetengan

\section{I.PENDAHULUAN}

Saat ini banyak objek wisata yang bermunculan diberbagai tempat, namun kebanyakan hanya berupa tempat rekreasi hiburan keluarga yang kurang memberikan nilai pendidikan bagi para pengunjungnya. Sementara objek wisata seperti "Museum Budaya Watu Pinawetengan" yang mempunyai nilai sejarah tinggi justru tidak banyak kita jumpai, selain itu pengunjung objek wisata museum budaya watu pinawetengan menurun.

Museum budaya watu pinawetengan merupakan salah satu objek wisata yang terdapat di desa Tompaso, Sulawesi Utara. Museum budaya watu Pinawetengan ini memberikan banyak pengetahuan mengenai sejarah peninggalan di watu Pinawetengan. Namun banyak orang masih enggan untuk mengunjungi dan mendapatkan pengetahuan dari museum budaya watu pinawetengan tersebut karena menganggap kurang menarik untuk ditujukan sebagai tujuan wisata. Bahkan masyarakat sulawesi utara sendiri belum banyak yang mengetahui tentang lokasi dan seperti apakah museum budaya watu pinawetengan tersebut.

Untuk mengatasi keadaan yang demikian, maka perlu diadakan usaha-usaha penyampaian informasi dan dokumentasi yang dikemas dengan menarik mengenai informasi tentang museum budaya watu pinawetengan berupa video animasi. Video animasi ini akan mempermudah masyarakat untuk lebih mengenal museum budaya watu pinawetengan dan informasi dari objek-objek didalamnya dengan berbasis 3 dimensi, sehingga rasa keingintahuan masyarakat tentang museum budaya watu pinawetengan akan bertambah. Berdasarkan latar belakang masalah tersebut, penulis memandang penting mengangkat kasus di atas ke dalam skripsi ini dengan mengambil judul: "Perancangan Animasi 3D Objek Wisata Museum Budaya Watu Pinawetengan"

\section{LANDASAN TEORI}

\section{A. Definisi Rancang Bangun}

Menurut Pressman (2002), perancangan merupakan serangkaian prosedur untuk menerjemahkan hasil analisa dari sebuah sistem ke dalam bahasa pemrograman untuk mendeskripsikan dengan detail bagaimana komponenkomponen sistem diimplementasikan. Menurut Al-Bahra (2005), perancangan adalah kegiatan yang memiliki tujuan untuk mendesain sistem baru yang dapat menyelesaikan masalah-masalah yang dihadapi perusahaan yang diperoleh dari pemilihan alternatif sistem yang terbaik.

Sedangkan pengertian bangun atau pembangunan sistem menurut Pressman (2002), kegiatan menciptakan sistem baru maupun mengganti atau memperbaiki sistem yang telah ada baik secara keseluruhan maupun sebagian.

Dengan demikian pengertian rancang bangun merupakan kegiatan menerjemahkan hasil analisa ke dalam bentuk paket perangkat lunak kemudian menciptakan sistem tersebut ataupun memperbaiki sistem yang sudah ada.

\section{B. Multimedia}

Dalam industri elektronika, multimedia adalah kombinasi dari komputer dan Video atau multimedia secara umum kombinasi dari 3 elemen yaitu suara, gambar, dan text atau multimedia adalah kombinasi yang paling sedikit dua media input atau output dari data media ini dapat Audio (suara, musik), animasi, Video, text, grafik, dan gambar atau multimedia merupakan alat yang dapat menciptakan presentasi yang dinamis dan interaktif yang mengkombinasikan text, garik, animasi, Audio dan gambar Video (Suyanto, 2005).

Multimedia di manfaatkan juga dalam bisnis dan pendidikan. Di dunia pendidikan, multimedia digunakan sebagai media pengajaran, baik dalam kelas maupun secara sendiri-sendiri atau otodidak. Di dunia bisnis, multimedia di gunakan sebagai media profil perusahaan, profil produk, bahkan sebagai media kios informasi dan pelatihan dalam sistem e-learning. 


\section{Animasi}

Definisi animasi sendiri berasal dari kata 'to animate' yang berarti menggerakan melalui perubahan sedikit demi sedikit dan teratur sehingga memberikan kesan hidup. Animasi adalah proses penciptaan efek gerak atau efek perubahan bentuk yang terjadi selama beberapa waktu. Animasi juga merupakan suatu teknik pengambilan gambar berurut sedemikian rupa hingga penonton merasakan adanya ilustrasi gerakan (motion) pada gambar yang di tampilkan. Definisi tersebut mengartikan bahwa benda-benda mati dapat "dihidupkan". Pengertian tersebut hanyalah merupakan istilah yang memiripkan, dalam arti tidak harus di terjemahkan secara denotatif, melainkan symbol yang menyatakan unsur kedekatan ( Zaharrudin,2007).

\section{3 Dimensi}

Berbeda dengan desain 2 dimensi yang hanya mengenal 2 parameter yaitu panjang dan lebar. Dalam konsep 3 DImensi, kita bias mendapatkan dimensi ketebalan. Obek 3 dimensi dipresentasikan didalam sebuah bidang yang terbilang memiliki 3 buah koordinat axis yang terdiri dari sumbu X, Y, dan $\mathrm{Z}$. Axis $\mathrm{X}$ adalah axis mendatar atau horizontal, axis $\mathrm{Y}$ adalah axis tegak atau vertikal, sedangkan axis $Z$ adalah axis yang menembus layar monitor kedalam (menunjukkan kedalaman ruang).

\section{E. Objek Wisata}

Objek wisata adalah tempat tujuan wisata utama yang dijadikan tempat rekreasi bagi para wisatawan, sedangkan wisata adalah kegiatan perjalanan yang dilakukan manusia maupun kelompok untuk mengunjugi suatu destinasi tertentu dengan tujuan rekreasi, mempelajari keunikan daerah wisata, pengembangan diri dan sebagainya dalam kurun waktu yang singkat atau sementara waktu (WTO: 1999).

\section{F. Pengertian Museum}

Kata museum berasal dari bahasa Yunani yaitu mouseion yang berarti tempat para muse. Muse adalah sembilan anak wanita Dewa Zeus yang memberikan inspirasi pada seniman. Yang kemudian mouseion tersebut dijadikan nama kuil tempat memuja dewi-dewi tersebut. Pada perkembangannya, mouseion dipakai sebagai tempat penyimpanan hadiah dan persembahan untuk dewa dari para umat (Encarta Researcher, 2003).

Menurut Kamus Besar Bahasa Indonesia (1990 : 601) museum / museum / $\mathrm{n}$ gedung yang digunakan sbg tempat untuk pameran tetap benda-benda yg patut mendapat perhatian umum, seperti peninggalan sejarah, seni dan ilmu, tempat menyimpan barang kuno.

\section{G. Objek Wisata Museum Budaya Watu Pinawetengan}

Minahasa merupakan bagian dari nusantara yang dikenal memiliki sejarah panjang keberadaannya. Sejarah panjang suku bangsa yang secara administrasi mendiami wilayah Sulawesi Utara ini membentuk tatanan kebudayaan yang adiluhung dan berekses pada terciptanya kesenian tradisional Minahasa.

Untuk menjaga dan melestarikan budaya tradisional Minahasa di tengah maraknya kebudayaan pop (popular culture), Yayasan Institut Seni Budaya Sulawesi Utara pada 2009 mendirikan sebuah museum yang bernama Museum Pinawetengan. Museum yang berada di dalam Kompleks Pusat Kebudayaan Sulawesi Utara ini berlokasi di kawasan Tompaso, Sulawesi Utara seperti terlihat pada Gambar 1.
Penggunaan nama Pinawetengan bukan tanpa sebab, Pinawetengan merupakan titik sentral dari kebudayaan Minahasa. Ari, seorang penjaga situs bersejarah Watu Pinawetengan mengungkapkan, Pinawetengan dianggap batu suci bagi masyarakat Minahasa, di tempat bebatuan yang berada di perbukitan Tonderukan itulah para leluhur Minahasa duduk berunding dan bermusyawarah.

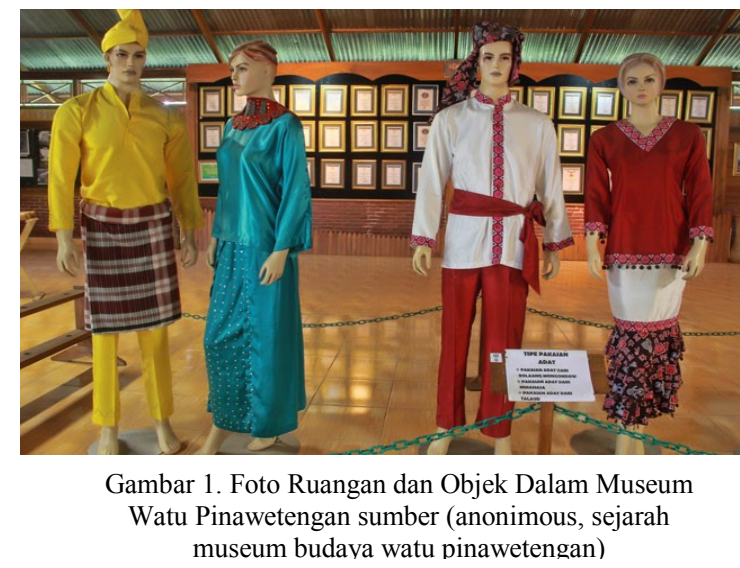

H. Blender

Blender adalah software 3D pada komputer yang gratis dan open source seperti pada Gambar 2.3. Blender digunakan untuk membuat film animasi, efek visual, aplikasi 3D interaktif atau Video game. Fitur Blender termasuk pemodelan 3D, unwrapping $\mathrm{UV}$, texturing, rigging dan skinning, fluid and smoke simulation, particle simulation, animating, match moving, camera tracking, rendering, Video editing dan compositing. Blender juga memiliki built-in game engine.

\section{METODE PENELITIAN}

Bentuk - bentuk metode penelitian penulis sebagai berikut:

\section{Penentuan Ide Cerita}

Penentuan Ide cerita merupakan tahap dimana penulis menentukan ide dan tema dari hasil pengamatan diMuseum Budaya Watu Pinawetengan, dan hasil konsultasi dari beberapa dosen sehingga dibuatlah menjadi judul skripsi Perancangan Aanimasi 3D Objek Wisata Museum Watu Pinawetengan.

\section{Pengumpulan Data}

Metode pengumpulan data yang dilakukan dalam penelitian ini adalah sebagai berikut:

\subsection{Observasi}

Pengumpulan data dengan dengan melakukan pengamatan secara langsung terhadap objek penelitian seperti: museum watu pinawetengan, terompet terbesar didunia, roda pacu mini, lesung, alat musik kolintang, kuali (blanga), bolotu, gergaji besar tua, dan sepeda kumbang tua.

\subsection{Wawancara}

Pengumpulan data dengan cara melakukan komunikasi dan wawancara secara langsung dengan pihak di Objek Wisata Museum Budaya Watu Pinawetengan mengenai data yang berhubungan dengan masalah yang akan di bahas. 


\section{Metode Perancangan}

Pada metode atau langkah-langkah dalam perancangan terdapat tiga tahapan pembuatan yaitu : Tahap Pra-Produksi, Tahap Produksi Dan Tahap Pasca Produksi seperti pada gambar 2.

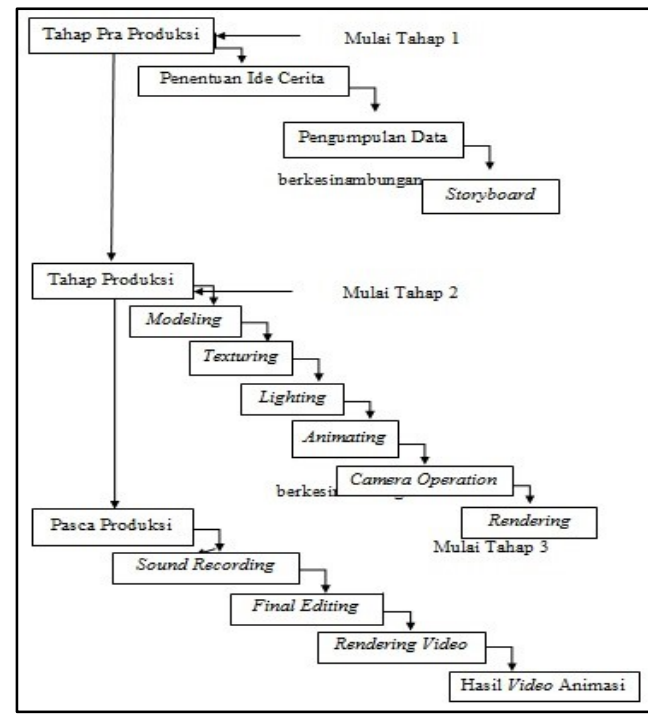

Gambar 2. Langkah- Langkah Video Animasi.

\section{HASIL DAN PEMBAHASAN}

\section{Modeling Objek}

Pada tahap ini penulis membuat atau memodeling objekobjek yang akan di gunakan dalam pembuatan Objek Wisata WatuPinawetengan termasuk gedung museum itu sendiri.

Dalam pembuatan modeling objek- objek dimuseum dan gedung museum memakai objek cube, Plane, Cylinder, dan Ico Sphare, kemudian pembentukan model objek dilakukan pada Menu Edit Mode dengan bantuan fungsi ekstrude, scale, grab, rotation, join hingga terbentuklah objek sesuai dengan keinginan penulis dan objek aslinya yang ada di dalam museum WatuPinawetengan.

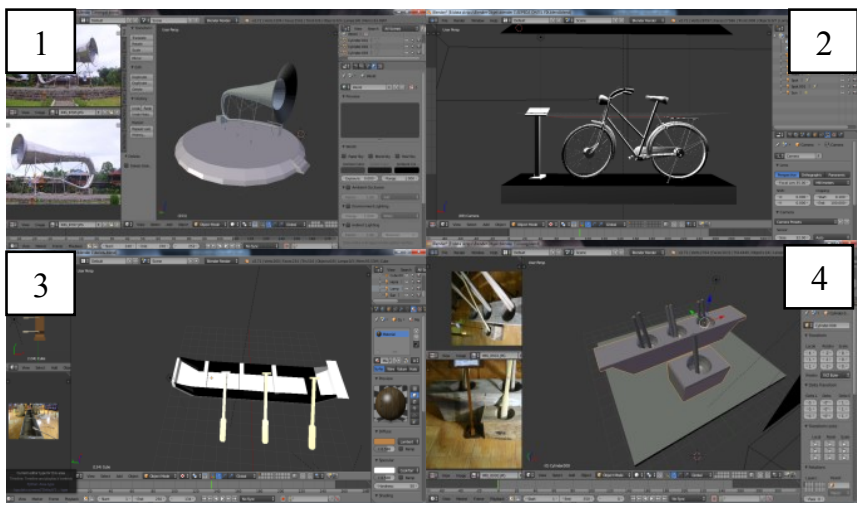

Gambar 3. Modeling Objek (1. Terompet, 2. Sepeda Kumbang Tua, 3. Bolotu, 4. Lesung)

\section{Texturing Objek}

Pada proses teksturing ini penulis menambahkan tekstur dan material atau warna yang sesuai dengan objek aslinya sehingga terlihat lebih nyata dan natural. Proses teksturing dalam aplikasi blender dapat dibuat dengan menggunakan tools material yang ada pada kolom properties pada aplikasi blender, seperti pada gambar 4 .

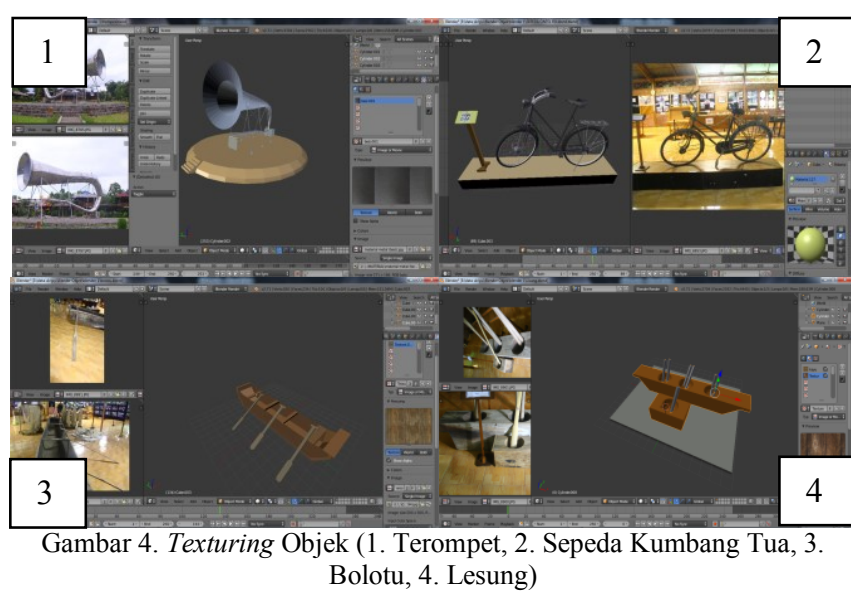

\section{Lighting}

Pada tahap Lighting penulis melakukan proses pemberian cahaya pada objek model sehingga diperoleh kesan visual yang realistis. Lamp atau lampu terdapat beberapa macam di antaranya point, sun, spot, hemi, dan area, pada tahap ini penulis mengunakan ada dua macam yaitu Spot dan Sun.

Lamp spot digunakan penulis untuk memberikan efek cahaya kepada objek yang dituju dan daerah sekitarnya, untuk menambahkan objek lampu yaitu dengan cara pergi ke header, pilih add, lamp, spot, untuk mengatur kekuatan cahaya kita gunakan energy, seperti yang terlihat pada gambar 5 .

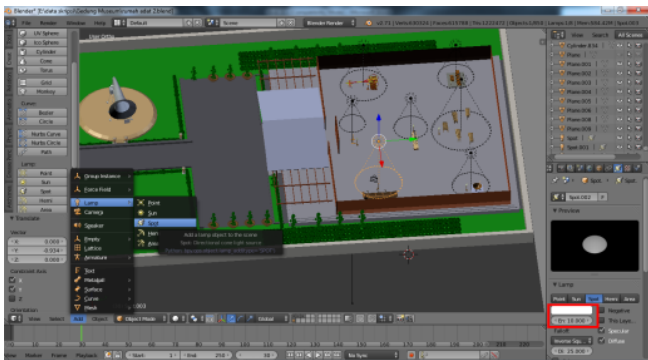

Gambar 5. Lighting Spot

Lamp Sun digunakan oleh penulis untuk memberikan efek sinar matahari yang berwarna putih, dengan cahaya yang dapat diatur menggunakan energy, energy yang di gunakan berada pada range 1.680 seperti yang sudah digunakan

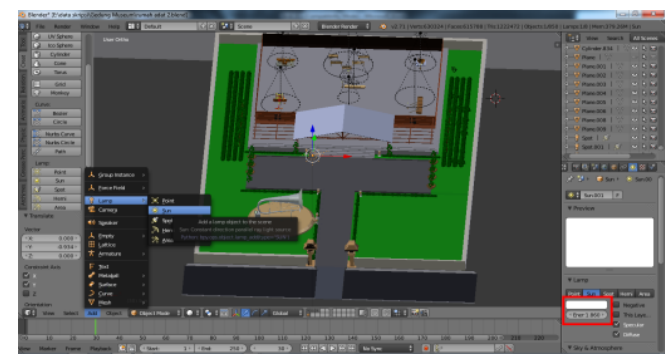

Gambar 6. Lighting Sun

\section{Animating}

Pada bagian animating penulis membuat animasi camera tracking, pergerakan objek kemera sesuai dengan mengikuti storyboard. Pembuatan animasi sendiri dilakukan secara manual dengan masuk pada tampilan drop sheet dan menambahkan key frame serta mengatur time line agar dapat 
lebih mudah menyesuaikan dengan objek dalam museum, seperti pada gambar 7 .

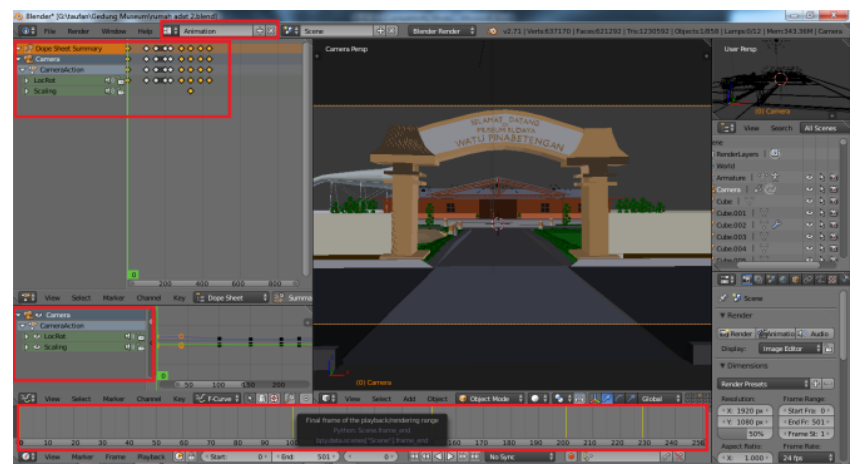

Gambar 7. Pengaturan Animating

\section{Camera Operation}

Pada tahap ini adalah proses pembuatan camera tracking masih dalam tahap animating tools, Camera tracking adalah merupakan cara untuk melihat model 3D yang di buat dengan pandangan camera yang berjalan sendiri mengikuti suatu objek, penulis memasukan objek empty sebagai fokus dari camera pada animasi, seperti pada gambar 8 .

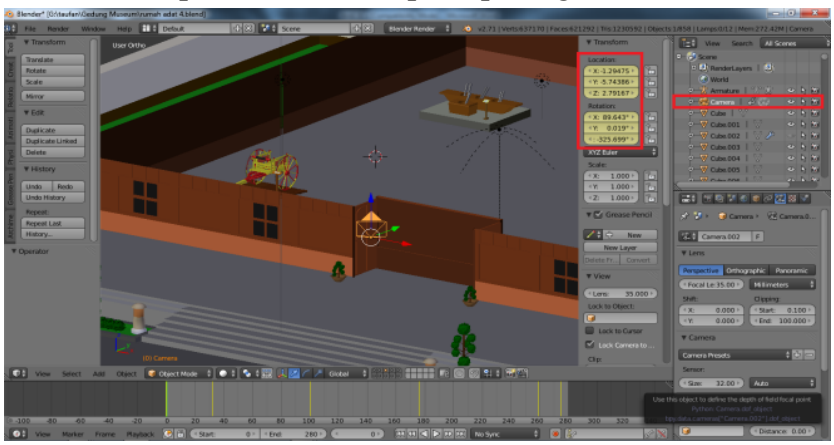

Gambar 8. Pengaturan dan letak Camera

\section{Rendering Objek}

Rendering adalah tahap penyatuan keseluruhan proses modeling, texturing, lightning, animating, dan camera operation untuk menjadi satu buah file Video yang dapat kita atur format, encoding, Audio dan lain-lain sesuai kebutuhan kita. Proses rendering dilakukan pada setiap adegan satu demi satu hingga menjadi beberapa Video animasi 3D. Proses rendering dilakukan pada tools render yang terdapat pada kolom proprties dengan menekan tombol Animation.

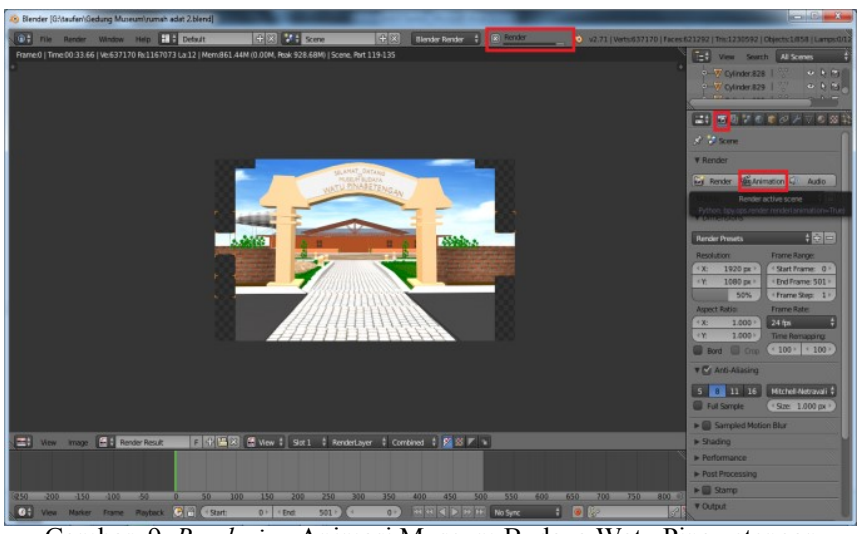

Gambar 9. Rendering Animasi Museum Budaya Watu Pinawetengan

\section{Record Suara Dan Instrumen Musik}

Proses perekaman suara dilakukan dengan menggunakan software Adobe Auditions 3.0, dengan file format perekaman menjadi format .wav, seperti pada gambar 10 .

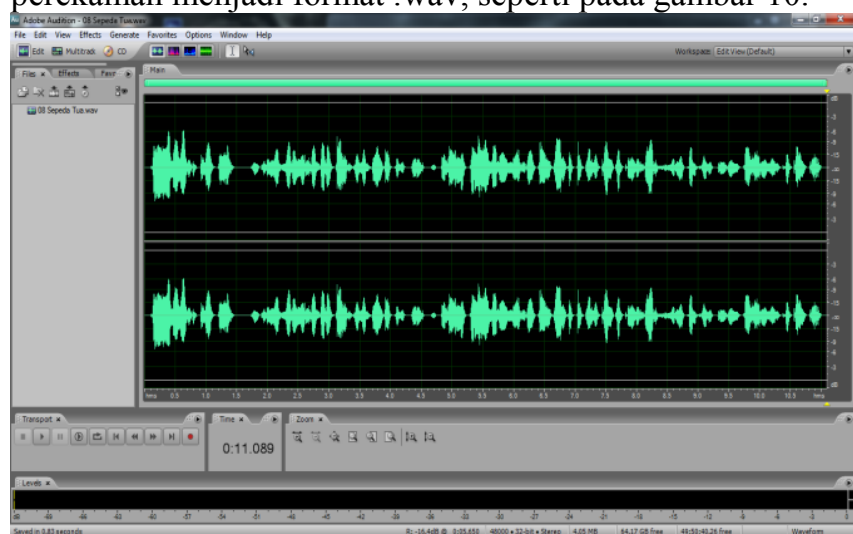

Gambar 10. Proses Perekaman Dubbing Suara

Pada gambar 11. Merupakan file audio hasil dari perekaman suara dan musik yang akan di import pada aplikasi Adobe Premiere Pro untuk digunakan dalam Video animasi 3D objek wisata museum budaya Watu Pinawetengan.

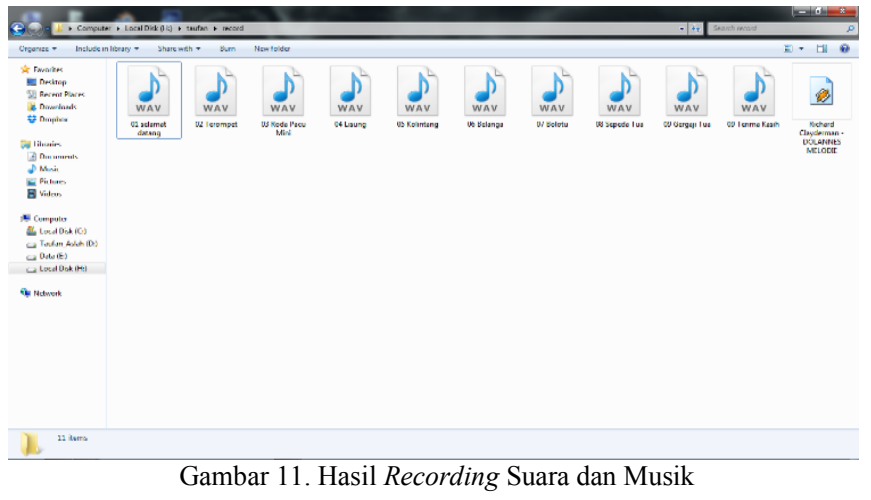

\section{Final Editing Video}

Final Editing merupakan bagian terakhir dari proses pembuatan Video perancangan animasi 3D objek wisata museum budaya watu Pinawetengan. Dimana semua file vieo 3 dimensi hasil render dari aplikasi Blender dan file Audio yang dibuat diaplikasi Adobe Audition 3.0 di import kedalam aplikasi Adobe Premiere Pro untuk disatukan dan dibuat sesuai dengan storyboard yang ada,seperti pada gambar 12 .

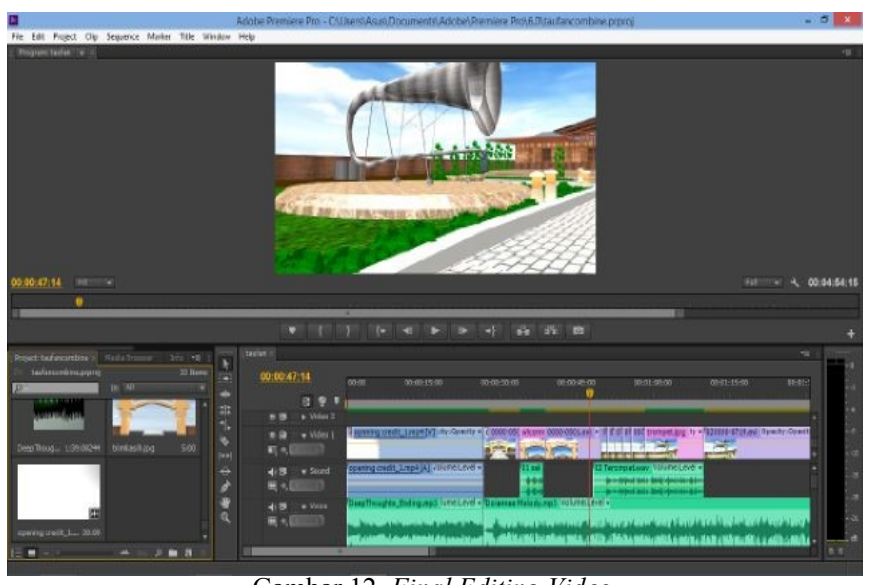

Gambar 12. Final Editing Video 


\section{Final Rendering Video}

Final Rendering merupakan tahap akhir dari pembuatan Video Animasi 3D pada aplikasi Adobe Premiere Pro dengan output yaitu Animasi 3D Objek Wisata Museum Budaya Watu Pinawetengan seperti pada gambar 13 merupakan proses untuk mengexport file Video Animasi 3D Objek Wisata Museum Budaya Watu Pinawetengan yang berdurasi 00:06:30 menit, seperti pada gambar 13 .

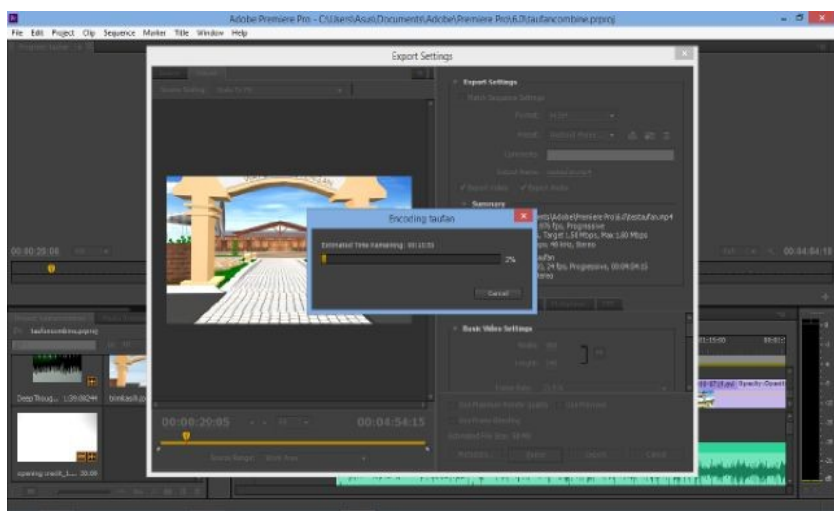

Gambar 13. Final Rendering Video

\section{Hasil Video Animasi 3D}

Details hasil dari Video Animasi 3D Objek Wisata Museum Budaya Watu Pinawetengan menjadi format file .mp4 beresolusi $960 \times 540$ pixel, frame yang digunakan yaitu $23,98 \mathrm{Fps}$, Bite rate Audio yaitu $157 \mathrm{Kbit} / \mathrm{sec}$ berdurasi 06 menit 30 detik dan ukuran file 77,1 MB, seperti pada gambar 14.

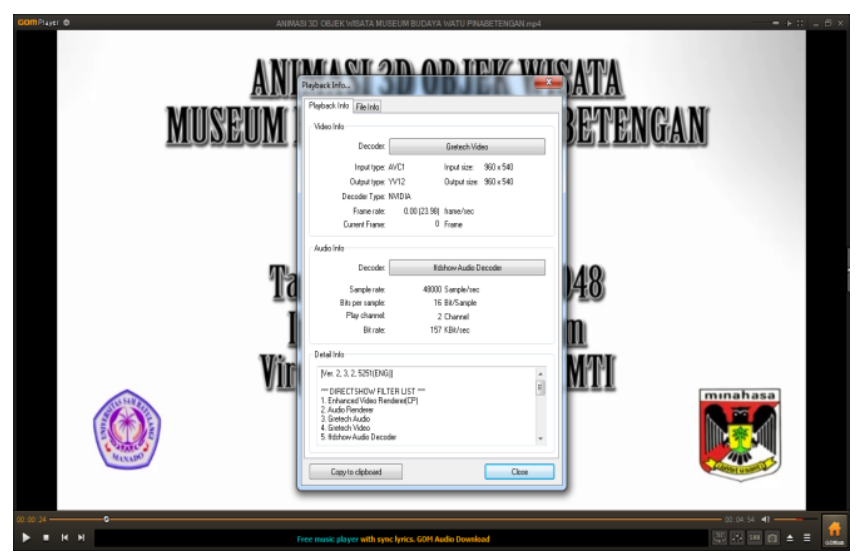

Gambar 14. Properties Video Animasi Museum Budaya Watu Pinawetengan.

Gambar 15, ini merupakan tampilan opening atau bagian awal dari hasil Video Animasi 3D Objek Wisata Museum Budaya Watu Pinawetengan.

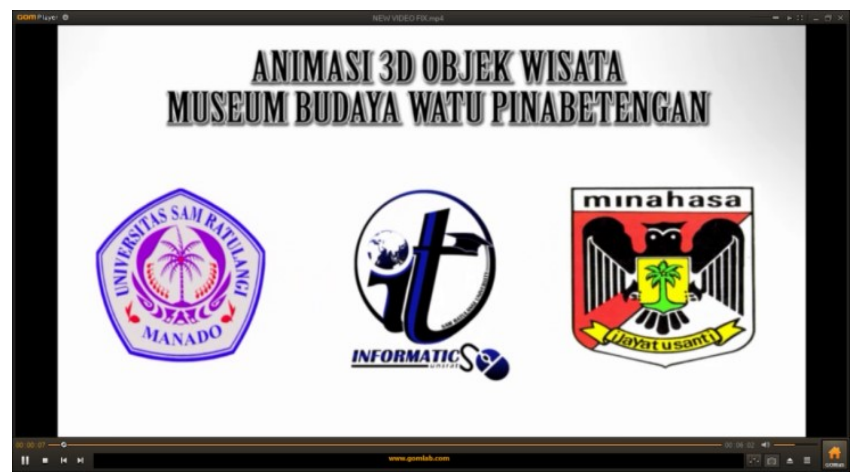

Gambar 15. Hasil Opening Video Animasi Museum Budaya Watu Pinaewetengan.
Pada gambar 16. Video menunjukan peta lokasi museum budaya watu pinawetengan disertai dengan jarak, dan waktu disertai icon lokasi dan objek mobil yang bergerak menuju ke lokasi museum budaya Watu Pinawetengan.
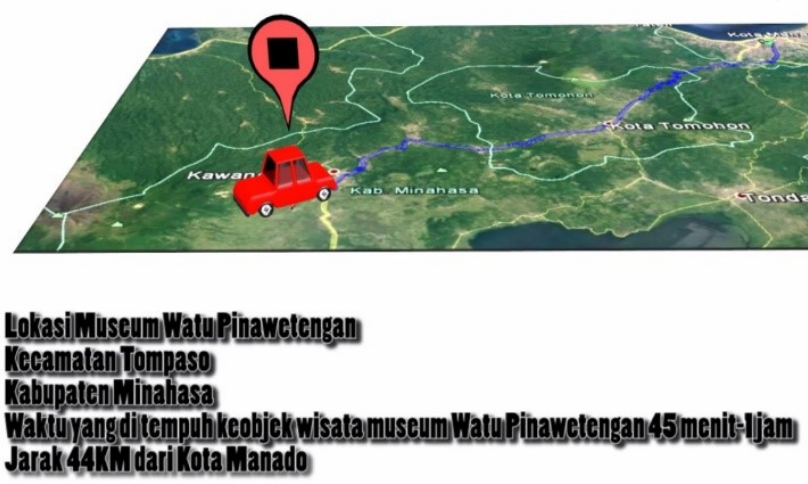

Gambar 16. Peta Lokasi, Jarak, Dan Waktu Tempuh Menuju Museum Budaya Watu Pinawetengan

Pada gambar 17, camera mulai masuk kedalam lingkungan museum budaya Watu Pinawetengan dan meliahat sekitar lingkungan museum.

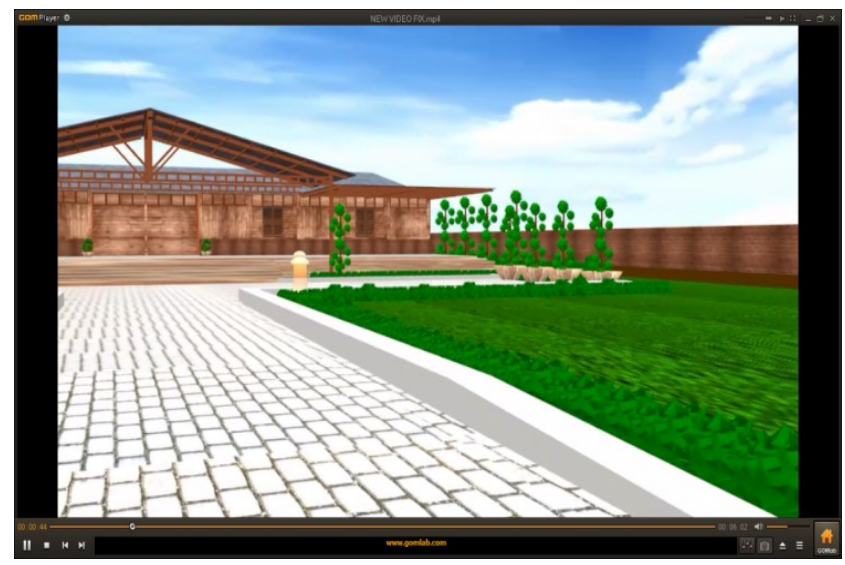

Gambar 17. Camera Mulai Masuk Dan Melihat Sekeliling Museum

Pada gambar 18, Camera berhenti didekat Terompet Terbesar di Dunia, serta adanya audio dan text penjelasan dari objek terompet terbesar didunia tersebut.

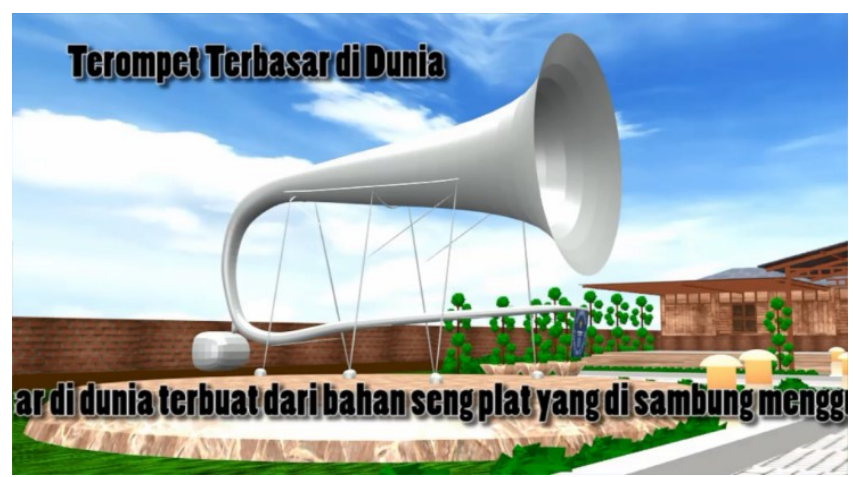

Gambar 18. Objek Pertama dalam lingkungan Museum Terompet Terbesar

Pada Gambar 19. Camera bergerak menuju kedalam bangunan museum dan melihat isi dari dalam banguanan museum tersebut. 


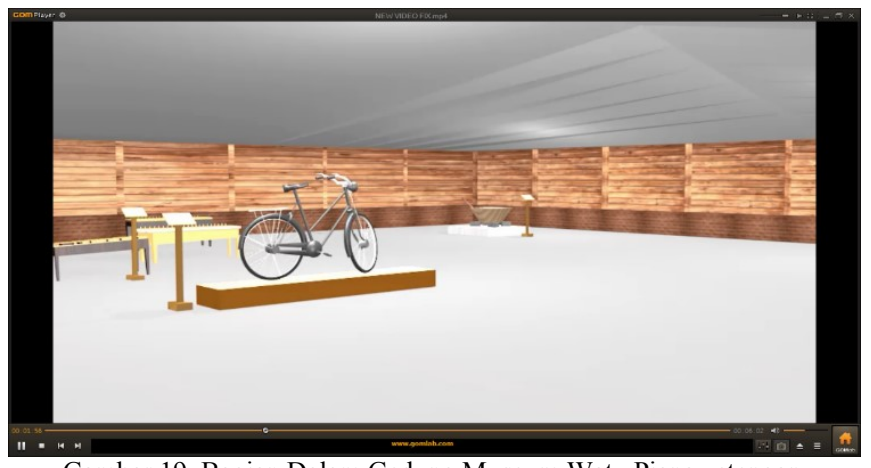

Gambar 19. Bagian Dalam Gedung Museum Watu Pianawetengan

\section{PENUTUP}

\section{A. Kesempulan:}

Setelah menyelesaikan proses pembuatan skripsi tentang "Perancangan Animasi 3D Objek Wisata Museum Budaya Watu Pinabetengan" ini penulis dapat mengambil beberapa kesimpulan, sebagai berikut:

Objek dalam Animasi 3D objek wisata museum budaya watu pinawetengan yang dihasilkan yaitu teompet terbesar di dunia, bolotu, sepeda kumbang,belanga, roda pacu mini, lisung gergaji besar tua, alat musik kolintang, bangunan museum dan benda bersejarah lainnya dapat di buat dengan bantuan foto.

1) Bangunan museum yang di buat tidak memiliki skala.

2) Penggunaan metodologi yang tepat dapat mempermuda pengerjaan pembuatan animasi, contoh metode yang digunakan yaitu Proses Produksi Multimedia yang meliputi Pra Produksi (preproduction), Produksi (production), dan Pasca Produksi (post-production).

3) Video yang dihasilkan menjadi format .mp4 beresolusi 960x540 Pixel, jumlah frame yang digunakan yaitu $23,98 \mathrm{Fps}$, dengan bite rate audio yaitu $157 \mathrm{Kbit} / \mathrm{sec}$. Durasi yang pada video yaitu 06menit 30detik dan dengan ukuran file sebesar 77,1 MB.

4) Video animasi 3D ini juga memberikan informasi dan pengetahuan sejarah-sejarah bagi para pengunjung museum budaya watu pinabetengan.

\section{B. Saran}

Setelah melalui keseluruhan proses pembuatan skripsi ini, penulis memiliki begitu banyak kekurangan dalam pembuatanya oleh karena itu perlu dibahas secara rinci nantinya.

Penulispun memikirkan beberapa hal yang sebaiknya di lakukan untuk membantu dalam menyempurnakan suatu pembuatan skripsi dalam bidang multimedia dikemudian hari antara lain

1) Dalam perkaman suara sebaiknya di lakukan di tempat yang sunyi tidak terganggu dengan suara- suara lainya agar hasil suara yang di rekam dapat terdengar dengan jelas dan bersih.

2) Dalam pembuatan animasi 3 dimensi dibutuhkan perangkat komputer yang memadai khususnya dalam melakukan animation atau menggerakan objek dan rendering minimalnya processor Intel Core TM i5-
421OU CPU up to $2.70 \mathrm{GHz}$, Memory 4 GB DDR3, HDD 500 GB Seagate dan VGA Nvidia GeForce 635M-2GB.

3) Segala komponen yang diperlukan harus dipersiapkan sebaik mungkin untuk mencegah kekurangan pada proses pembuatan animasi 3D.

4) Bidang multimedia sangatlah pesat pertumbuhanya oleh karena itu sangatlah penting untuk terus memperbaharui pengetahuan kita sesuai dengan keadaan terkini.

\section{DAFTAR PUSTAKA}

[1] Aditama, S. 3 Tahap Alur Produksi Multimedia. https://multimedialicious.com/tag/3-tahap-alurproduksi-multimedia/. diakses pada tanggal 23 Desember 2016.

[2] Anonimous, Sejarah Museum Budaya Watu Pinawetengan.http://www.indonesiakaya.com/jelajah -indonesia/detail/mengenal-minahasa-dari-dekat-dimuseum-pinawetengan. diakses pada tanggal 25 November 2015.

[3] Al-Bahra bin Ladjamudin. Analisis dan Desain Sistem Informasi. Yogyakarta : Graha Ilmu. 2005

[4] Aplikasi Blender, Tersedia di http://www.blender.org. diakses pada tanggal 25 november 2015.

[5] Encarta Researcher, Pengertian Museum. 2003. http://globallavebook.co.id/2014/02/pengertianmuseum-menurut-para-ahli.html diakses pada 12 Maret 2017.

[6] WTO. 1999. Pengertian Objek Wisata http://www.definisimenurutparaahli.com/pengertianwisata/ diakses pada tanggal 08 February 2017.

[7] Zaharuddin. 2007. Pengertian Animasi http://sir.stikom.edu/1041/5/BAB_II.pdf diakses pada tanggal 20 Juni 2016.

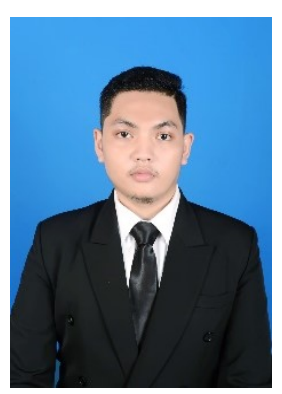

Sekilas dari penulis dengan nama lengkap Taufan Yusuf Aslah, lahir pada tanggal 10 Februari 1993 di Manado, Provinsi Sulawesi Utara. Anak ke-2 dari 2 bersaudara, dengan orang tua bernama Alm.Hi. Afandy Ibrahim Aslah dan ibu bernama Hj. Fauziya Mastiya Dawali. Dengan pendidikan pertama di Taman Kanak-Kanak Merpati Pos, kemudian melanjutkan ke SD Negeri 11 Manado, melanjutkan ke SMP Negeri 6 Manado, dan pada tahun 2007 melanjutkan ke SMA Negeri 7 Manado. Setelah lulus sekolah menengah atas pada tahun 2010 penulis melanjutkan ke Perguruan Tinggi tepatnya di Universitas Sam Ratulangi Manado, Fakultas Teknik, Jurusan Elektro, Program Studi Informatika. Penulis membuat skripsi untuk memenuhi syarat sarjana (S1), dengan judul Perancangan Animasi 3D Objek Wisata Museum Budaya Watu Pinawetengan yang di bimbing oleh dua dosen Teknik Informatika yaitu mner Ir Hans F. Wowor M.Kom dan enci Virginia Tulenan S.Kom., MTI dan mengikuti sidang Skripsi pada tanggal 04 Mei 2017, sehingga pada tanggal 30 Juni 2017 penulis resmi lulus di Teknik Informatika Universitas Sam Ratulangi Manado dengan predikat sangat memuaskan. 